\title{
Inventarisasi dan Status Konservasi Herpetofauna di Punggualas, Taman Nasional Sebangau
}

\author{
Inventory and Conservation Status of Herpetofauna in Punggualas, \\ Sebangau National Park
}

\author{
Andri Maulidi ${ }^{1 *}$, Muhammad Rizki ${ }^{1}$, Rabiatul Adawiyah ${ }^{1}$, Yohanes Edy Gunawan ${ }^{1}$, Yosua $^{2}$, \\ Adventus Panda ${ }^{1}$ \\ ${ }^{1}$ Program Studi Biologi, Fakultas Matematika dan Ilmu Pengetahuan Alam, Universitas Palangka Raya \\ ${ }^{2}$ Program Studi Pendidikan Biologi, Fakultas Keguruan dan Ilmu Pendidikan, Universitas Palangka Raya
}

*Alamat email: andrimaulidi@mipa.upr.ac.id

\begin{abstract}
Abstrak - Informasi tentang herpetofauna di Punggualas, Taman Nasional Sebangau telah dilakukan pada tahun 2015. Tujuan dari penelitian ini adalah untuk menginventarisasi jenis-jenis herpetofauna setelah empat tahun dari data terakhir di Punggualas, Taman Nasional Sebangau. Metode yang digunakan dalam penelitian ini adalah Visual Encountered Survey (VES) selama empat hari di sepanjang transek Kahiu dan Metarius. Hasil penelitian menunjukkan bahwa terdapat 11 spesies yang terinventarisasi yang terdiri dari delapan spesies reptile ( 7 famili) dan tiga spesies amfibi ( 3 famili). Temuan ini lebih sedikit dibandingkan literatur pada tahun 2015 yaitu sebanyak 33 spesies yang terdiri dari 17 spesies reptile (13 famili) dan 16 spesies amfibi (4 famili). Hal ini dikarenakan perbedaan luas daerah pengamatan, lama pengamatan, metode, jumlah orang pengamat, dan tingkat keahlian pengamat. Lima spesies ditemukan pada penelitian ini yang belum ditemukan pada tahun 2015 yaitu Homalopsis buccata, Ahaetulla prasina, Cyrtodactylus sp., Siebenrockiella crassicollis, dan Notochelys platynota. Terkait dengan status, 28 spesies herpetofauna berstatus Least Concern, tiga spesies berstatus Vulnerable, dan satu spesies berstatus Near Threatened. Enam spesies lainnya belum memiliki status konservasi di IUCN Red List. Perlu dilakukan penelitian berikutnya tentang jumlah populasi dan pengamatan pada daerah yang lebih luas.
\end{abstract}

Kata kunci: invetarisasi, status konservasi, herpetofauna, Punggualas

\begin{abstract}
Herpetofauna information in Punggualas, Sebangau National Park was conducted in 2015. The purpose of this study is to invent the species composition of herpetofauna after four years the information was released. The method used in this study was Visual Encountered Survey (VES) for 4 days along the Kahiu and Metarius transects. The results showed that 11 species were consisting of 8 reptile species ( 7 families) and 3 amphibian species ( 3 families). This finding is less than the literature in 2015 as many as 33 species consisting of 17 reptile species (13 families) and 16 amphibian species (4 families). It is likely due to differences in the area of observation, observation time, method, number of observers, and level of expertise of the observers, compared to the previous survey. There are 5 species found in this study that have not been found in 2015, namely Homalopsis buccata, Ahaetulla prasina, Cyrtodactylus sp., Siebenrockiella crassicollis, and Notochelys platynota. There are 28 species of Least Concern status, 3 species of Vulnerable status, and 1 species of Near Threatened status for conservation status. While 6 other species do not yet have conservation status on the IUCN Red List. Further research needs to be done on population numbers and observations in a wider area.
\end{abstract}

Keywords: inventory, conservation status, herpetofauna, punggualas

두 2020 Jurnal Jejaring Matematika dan Sains. This work is licensed under a $\underline{C C B Y-N C 4.0}$

\section{PENDAHULUAN}

Taman Nasional (TN) Sebangau merupakan salah satu dari dua Taman Nasional yang berada di Kalimantan Tengah. Secara administratif terletak di Kota Palangka Raya, Kabupaten Pulang Pisau dan Kabupaten Katingan. Taman Nasional Sebangau dibagi menjadi tiga kawasan yaitu Resort Sungai Koran, Resort Sungai Mangkok, dan Resort Punggualas. Kawasan Punggualas secara administratif terletak di Desa Karuing, Kecamatan Kamipang, Kabupaten Katingan.
Kawasan Punggualas sangat menarik karena terdiri dari hutan rawa gambut dan hutan rawa campuran. Hal tersebut memberikan potensi keanekaragaman hayati yang tinggi di dalamnya. Selain orangutan, di Punggualas menyimpan keanekaragaman hewan yang belum banyak digali dan diungkap. Beberapa penelitian terkait keanekaragaman hayati di Punggualas adalah penelitian tumbuhan obat [1]. Buku panduan visual dan identifikasi capung dan kupu-kupu di kawasan Punggualas [2]. Selain itu tersedianya buku panduan visual dan identifikasi lapang Reptil dan Amfibi di Punggualas [3]. 
Terdapat 17 spesies reptil dan 16 spesies amfibi di Punggualas [3]. Monitoring secara rutin terhadap amfibi dan reptil perlu dilakukan. Hal ini dikarenakan perlu adanya data dasar sebagai pembanding untuk survey yang dilakukan dimasa mendatang [4].

Penelitian ini bertujuan untuk menginventarisasi dan memahami status konservasi herpetofauna di kawasan Punggualas, TN Sebangau. Melalui penelitian ini diharapkan dapat memberikan sumbangsih data terkait jenis-jenis herpetofauna yang ada di kawasan Punggualas dan status konservasinya sebagai rekomendasi pengelolaan konservasi kedepan.

\section{METODE PENELITIAN}

Waktu dan Tempat

Penelitian ini dilaksanakan di wilayah Punggualas, di Desa Karuing, Kecamatan Kamipang, Kabupaten Katingan pada transek utama Kahiu dan Metarius.
Penelitian tersebut dilaksanakan pada tanggal 7-10 Desember 2019.

\section{Metode Penelitian}

Pengumpulan data menggunakan metode Visual Encounter Survey (VES) dengan batasan waktu [5] [6][7]. Sampling dilakukan pada pagi hari (07.00-10.00 WIB) untuk menemukan herpetofauna diurnal dan pada malam hari (18.00-21.00 WIB) untuk menemukan herpetofauna nokturnal. Identifikasi spesies menggunakan buku panduan identifikasi [8], [9], [10], dan [11]. Untuk semua spesies yang ditemukan diambil data dasar seperti koordinat GPS, tanggal dan waktu penemuan, dan data ekologi seperti suhu, $\mathrm{pH}$ air, dan $\mathrm{pH}$ tanah.

Status Konservasi

Penentuan status konservasi pada herpetofauna melalui Red List International Union for the Conservation of Nature and Natural Resources (IUCN) [12].

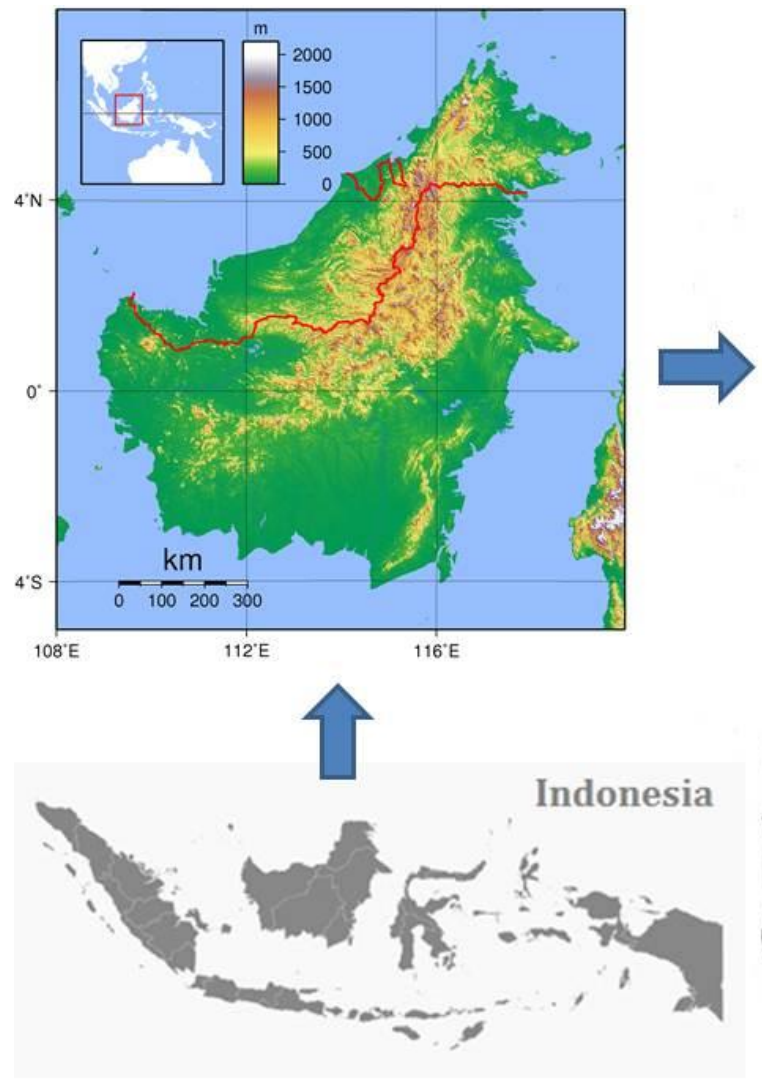

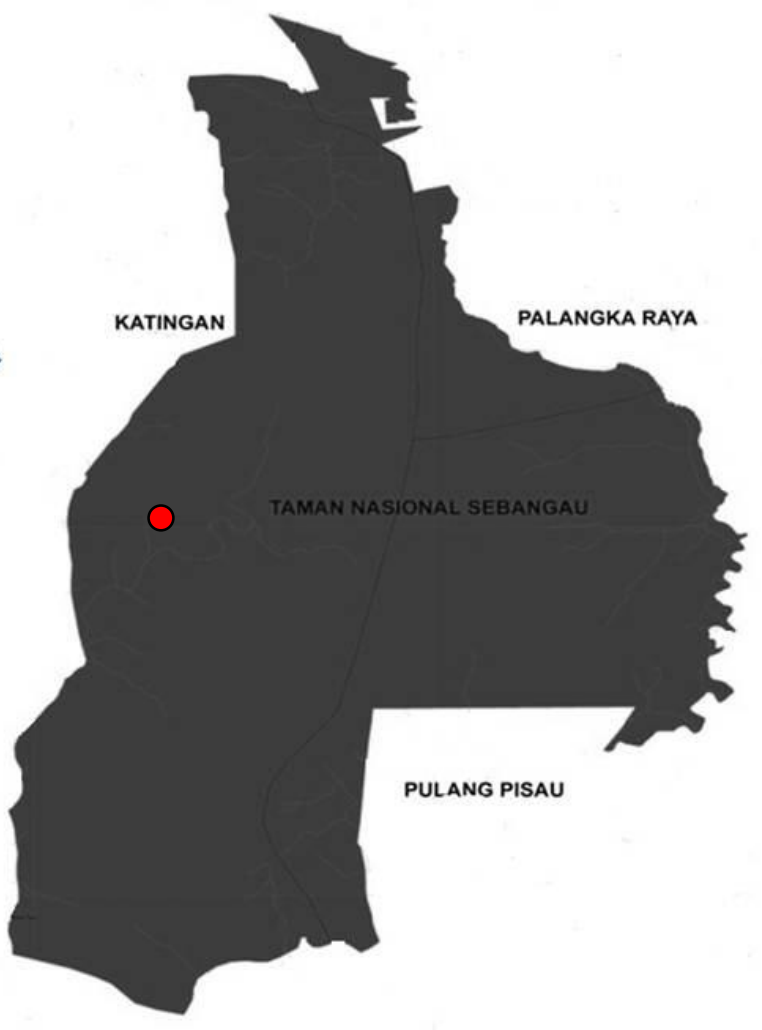

Gambar 1. Lokasi sampling di wilayah Punggualas, Taman Nasional Sebangau

\section{HASIL DAN PEMBAHASAN}

Pada tahun 2019, sebanyak 11 spesies herpetofauna terinventarisasi di Punggualas yang terdiri dari 8 spesies reptil (7 famili) dan 3 spesies amfibi (3 famili). Sedangkan pada sumber pustaka sebelumnya di tahun 2015, ditemukan 33 spesies herpetofauna yang terdiri dari 17 spesies reptil (13 famili) dan 16 spesies amfibi (4 famili) (Tabel 1). Jumlah herpetofauna yang ditemukan di
Punggualas baik dari tahun 2015 dan 2019 tidak lebih banyak jika dibandingkan dengan jumlah herpetofauna yang ada di TN Sebangau secara keseluruhan. Jumlah herpetofauna di TN Sebangau sebanyak 57 spesies yang terdiri dari 46 spesies reptil dan 11 spesies amfibi [13]. Hal ini dapat terjadi dikarenakan perbedaan ukuran daerah pengamatan, lamanya waktu sampling, metode sampling, jumlah orang yang melakukan sampling, dan kemampuan orang yang melakukan sampling [7]. Pada artikel ini tidak untuk membandingkan hasil survei pada 
tahun yang berbeda, akan tetapi tampilan data pada tabel satu tersebut bertujuan untuk menampilkan spesies apa saja yang pernah ditemukan di wilayah Punggualas.

Meskipun jumlah spesies yang ditemukan di tahun 2019 tidak lebih banyak, terdapat penemuan menarik yaitu 5 spesies reptil (4 famili) yang sebelumnya belum ditemukan ditahun 2015. Spesies tersebut yaitu Homalopsis buccata, Ahaetulla prasina, Cyrtodactylus sp., Siebenrockiella crassicollis, dan Notochelys platynota (Gambar 2). Untuk spesies H. bucatta, S. crassicollis, dan $N$. platynota merupakan record baru baik di wilayah Punggualas maupun secara luas di TN Sebangau. Hal ini menunjukkan perlu dilakukan penelitian lebih lanjut dengan daerah pengamatan yang lebih luas dikarenakan terdapat 22 jalur transek di wilayah Punggualas agar mendapatkan jenis-jenis lainnya yang berpotensi sebagai new record di wilayah ini ataupun new spesies, mengingat wilayah ini memiliki potensi yang besar terkait keanekaragaman hayati.

Berdasarkan IUCN Red List, status konservasi dari semua spesies yang pernah ditemukan di wilayah Punggualas baik pada tahun 2015 maupun 2019 terdiri dari Least Concern (LC), Vulnerable (VU), dan Near Threatened (NT). 28 spesies berstatus Least Concern, 3 spesies berstatus Vulnerable, dan 1 spesies berstatus Near Threatened. Sedangkan 6 spesies lainnya belum memiliki status konservasi di IUCN Red List ataupun belum teridentifikasi sampai pada tingkat spesies sehingga belum bisa menuliskan status konservasinya.

Tabel 1. Daftar Jenis Herpetofauna Yang Ditemukan Di Wilayah Punggualas

\begin{tabular}{|c|c|c|c|c|}
\hline Famili & Spesies & $\begin{array}{l}\text { Status } \\
\text { IUCN }\end{array}$ & Punggualas 2015* & Punggualas 2019 \\
\hline Pareidae & Aplopeltura boa & $\mathrm{LC}$ & $\sqrt{ }$ & \\
\hline Homalopsidae & Homalopsis buccata & $\mathrm{LC}$ & & $\sqrt{ }$ \\
\hline \multirow[t]{3}{*}{ Colubridae } & Ahaetulla prasina & $\mathrm{LC}$ & & $\sqrt{ }$ \\
\hline & Boiga dendrophila & - & $\sqrt{ }$ & \\
\hline & Gonyosoma oxycephalum & $\mathrm{LC}$ & $\sqrt{ }$ & \\
\hline Natricidae & Macropisthodon flaviceps & $\mathrm{LC}$ & $\sqrt{ }$ & \\
\hline Lamprophiidae & Psammodynastes pulverulentus & - & $\sqrt{ }$ & \\
\hline Natricidae & Xenochrophis trianguligerus & $\mathrm{LC}$ & $\sqrt{ }$ & \\
\hline Viperidae & Tropidolaemus subannulatus & $\mathrm{LC}$ & $\sqrt{ }$ & $\sqrt{ }$ \\
\hline Elapidae & Ophiophagus hannah & VU & $\sqrt{ }$ & \\
\hline Pythonidae & Malayopython reticulatus & $\mathrm{LC}$ & $\sqrt{ }$ & \\
\hline Agamidae & Draco maximus & $\mathrm{LC}$ & $\sqrt{ }$ & \\
\hline \multirow{3}{*}{ Gekkonidae } & Gecko sp. & - & $\sqrt{ }$ & \\
\hline & Hemidactylus garnotii & - & $\sqrt{ }$ & \\
\hline & Cyrtodactylus sp. & - & & $\sqrt{ }$ \\
\hline Lacertidae & Takydromus sexlineatus & $\mathrm{LC}$ & $\sqrt{ }$ & \\
\hline \multirow[t]{2}{*}{ Scincidae } & Apterygodon vittatum & $\mathrm{LC}$ & $\sqrt{ }$ & \\
\hline & Eutropis multifasciata & $\mathrm{LC}$ & $\sqrt{ }$ & $\sqrt{ }$ \\
\hline \multirow[t]{2}{*}{ Geoemydidae } & Siebenrockiella crassicollis & VU & & $\sqrt{ }$ \\
\hline & Notochelys platynota & VU & & $\sqrt{ }$ \\
\hline \multirow[t]{2}{*}{ Varanidae } & Varanus rudicollis & - & $\sqrt{ }$ & \\
\hline & Varanus salvator & $\mathrm{LC}$ & $\sqrt{ }$ & $\sqrt{ }$ \\
\hline \multirow[t]{2}{*}{ Bufonidae } & Duttaphrynus melanostictus & $\mathrm{LC}$ & $\sqrt{ }$ & \\
\hline & Pseudobufo subasper & $\mathrm{LC}$ & $\sqrt{ }$ & \\
\hline \multirow[t]{7}{*}{ Dicroglossidae } & Fejervarya cancrivora & $\mathrm{LC}$ & $\sqrt{ }$ & \\
\hline & Fejervarya limnocharis & $\mathrm{LC}$ & $\sqrt{ }$ & \\
\hline & Limnonectes ingeri & $\mathrm{LC}$ & $\sqrt{ }$ & \\
\hline & Limnonectes laticeps & $\mathrm{LC}$ & $\sqrt{ }$ & \\
\hline & Limnonectes leporinus & $\mathrm{LC}$ & $\sqrt{ }$ & \\
\hline & Limnonectes malesianus & NT & $\sqrt{ }$ & $\sqrt{ }$ \\
\hline & Occidozyga laevis & $\mathrm{LC}$ & $\sqrt{ }$ & \\
\hline \multirow{5}{*}{ Ranidae } & Odorrana hosii & $\mathrm{LC}$ & $\sqrt{ }$ & \\
\hline & Pulchrana baramica & $\mathrm{LC}$ & $\sqrt{ }$ & $\sqrt{ }$ \\
\hline & Hylarana erythraea & $\mathrm{LC}$ & $\sqrt{ }$ & \\
\hline & Hylarana nicobariensis & $\mathrm{LC}$ & $\sqrt{ }$ & \\
\hline & Hylarana raniceps & $\mathrm{LC}$ & $\sqrt{ }$ & \\
\hline \multirow[t]{3}{*}{ Rhacophoridae } & Polypedates colletti & $\mathrm{LC}$ & $\sqrt{ }$ & $\sqrt{ }$ \\
\hline & Polypedates leucomystax & $\mathrm{LC}$ & $\sqrt{ }$ & \\
\hline & Jumlah & & 33 spesies & 11 spesies \\
\hline
\end{tabular}

$*$ dari ref [3]

Tiga spesies yang berstatus Vulnerable yaitu Ophiophagus hanna dari famili Elapidae yang ditemukan pada tahun 2015 berdasarkan referensi [3] dan $S$. crassicollis, dan $N$. platynota yang ditemukan tahun 2019. Satu spesies yang berstatus Near Threatened adalah spesies Limnonectes malesianus. Pada spesies $S$. crassicollis, dan $N$. platynota memiliki status Vulnerable karena spesies ini memiliki ancaman seperti perdagangan untuk hewan peliharaan dan terganggunya habitat alami dari spesies tersebut. Untuk S. crassicollis merupakan 
spesies kedua tertinggi untuk jenis lokal yang diperdagangakan di Jakarta dan Bandung [14].

S. crassicollis (Black Marsh Turtle) merupakan spesies kura-kura yang memiliki ukuran tubuh yang kecil. Kura-kura ini ditemukan di aliran air sungai gambut pada malam hari. Kura-kura ini dikenal sebagai kura-kura pipi putih karena memiliki corak berwarna putih dibagian pipi. Sedangkan pada $N$. platynota ditemukan di genangan air yang dangkal. Ketika ditemukan, spesies ini mengeluarkan parasit yang ada di dalam tubuh. Informasi parasit yang pernah ditemukan dari spesies ini adalah dari Filum Nematoda [14]. Spesies Cissophyllus laverani merupakan new record untuk parasit nematode yang ditemukan pada $N$. platynota dari Desa Berong, Kalimantan Tengah [14]. Adanya parasit pada kura-kura ini menyadarkan kita untuk tidak sembarangan memelihara satwa liar karena akan timbul banyak kontak langsung dengan hewan tersebut. Akibatnya, ada peluang jenis nematode tersebut menjadi parasit bagi manusia.
Jika dilihat informasi status konservasi S. crassicollis, dan N. platynota pada $I U C N$, terakhir kali di nilai pada tahun 2000. Hal ini menunjukkan sudah hampir 20 tahun setelah dilakukan penilaian status konservasinya. Untuk itu, perlu adanya survei populasi pada kedua jenis kurakura tersebut sehingga dapat memberikan sumbangsih data untuk penilaian status konservasinya di IUCN.

Faktor abiotik seperti suhu udara, $\mathrm{pH}$ tanah dan $\mathrm{pH}$ air juga diukur dalam penelitian ini. Suhu udara berkisar antara $25^{\circ}-26^{\circ} \mathrm{C}, \mathrm{pH}$ air berkisar antara 3.9-4.0 dan $\mathrm{pH}$ tanah berkisar antara 4.2-4.8.

Pada buku panduan visual dan identifikasi amfibi dan reptil Punggualas, terdapat beberapa kekeliruan dalam penulisan nama latin (typo) dan gambar spesies. Pada buku tersebut tertulis Polypedates coletti, seharunya nama latin yang benar adalah Polypedates colletti. Selain itu, pada buku tersebut pada foto Limnonectes laticeps mirip dengan foto Pulchrana baramica yang seharusnya berbeda foto karena perbedaan spesiesnya sangat jelas.

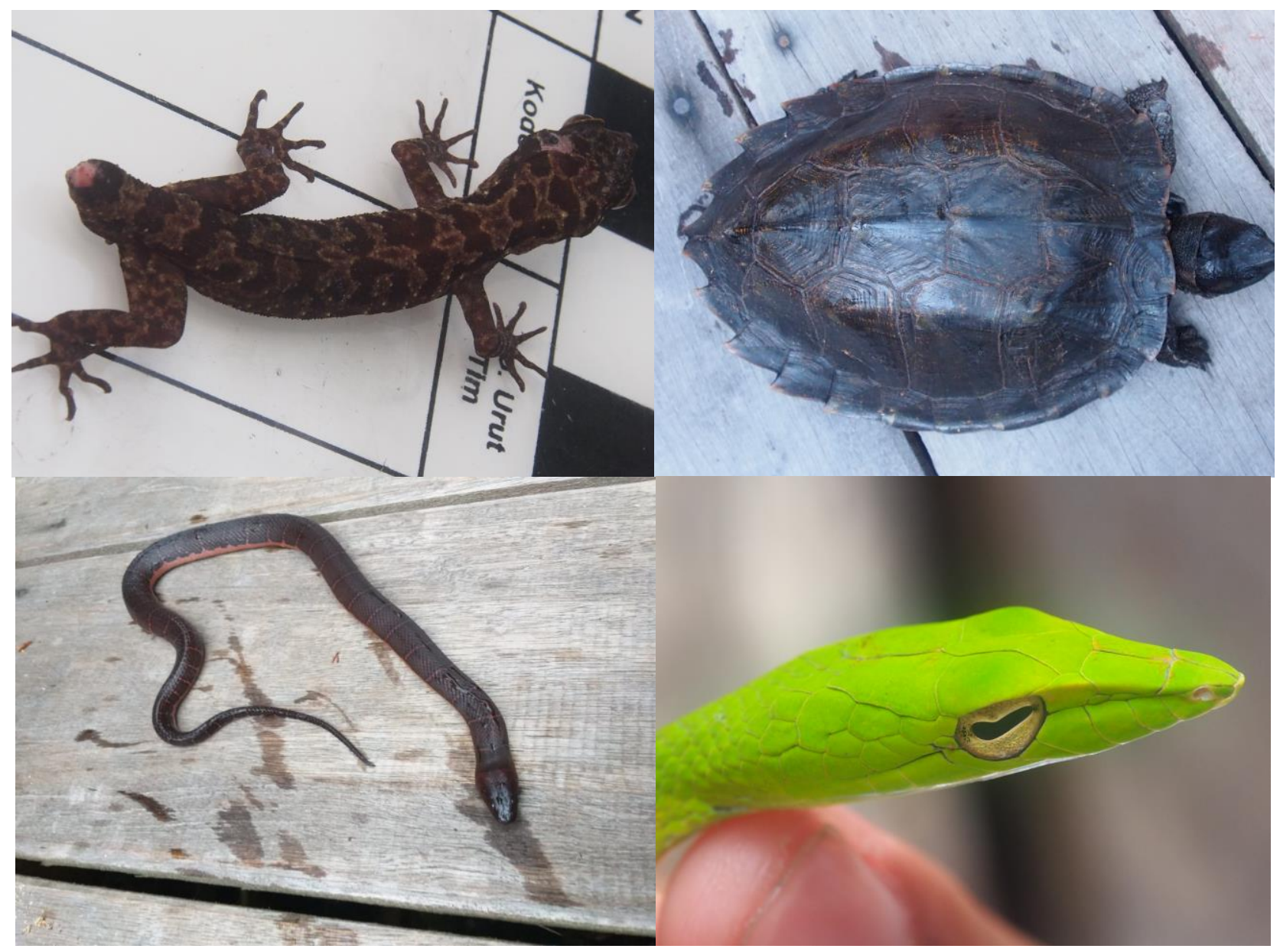




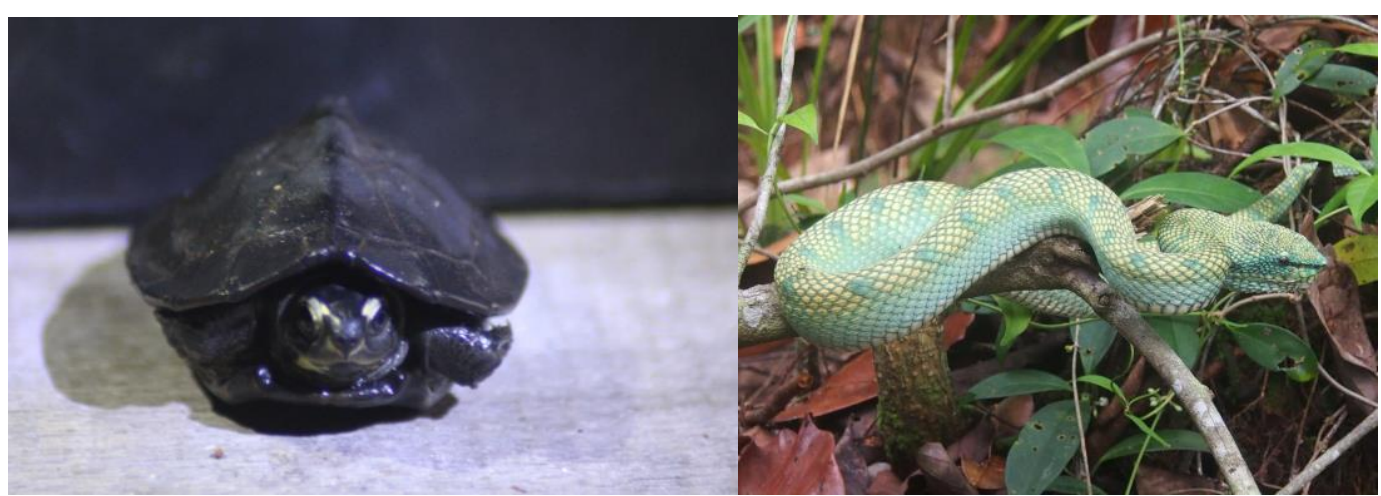

Gambar 2. Dokumentasi beberapa herpetofauna yang ditemukan di wilayah Punggualas pada penelitian ini. A) Cyrtodactylus sp., B) Notochelys platynota, C) Homalopsis bucatta, D) Ahaetulla prasina, E) Siebenrockiella crassicollis, F) Tropidolaemus subannulatus.

\section{SIMPULAN}

Berdasarkan jumlah herpetofauna yang diinventarisasi, jumlah yang ditemukan di tahun 2019 (11 spesies) lebih sedikit dibandingkan dengan yang pernah ditemukan di tahun 2015 (33 spesies). Hal menarik dari temuan ini adalah ditemukan 5 spesies yang belum pernah ditemukan sebelumnya. Dua dari spesies tersebut $S$. crassicollis dan $N$. platynota merupakan record baru untuk di wilayah Punggualas dan Taman Nasional Sebangau secara umum. Secara keseluruhan, terdapat 28 spesies berstatus Least Concern, 3 spesies berstatus Vulnerable, dan 1 spesies berstatus Near Threatened. Sedangkan 6 spesies lainnya belum memiliki status konservasi di IUCN Red List. Perlu dilakukan penelitian lebih lanjut terkait jumlah populasi terutama pada spesies yang Vulnerable dan penelitian dengan daerah pengamatan yang lebih luas agar mendapatkan jumlah spesies yang lebih banyak dan berpotensi menemukan spesies baru.

\section{UCAPAN TERIMA KASIH}

Terimakasih kepada SPTN Wilayah III TN Sebangau yang berada di Kasongan, Kabupaten Katingan yang telah mengizinkan untuk melakukan observasi lapang Program Studi Pendidikan Biologi FKIP Universitas Palangka Raya. Terimakasih juga kepada Ibu Elga Araina selaku dosen pembimbing dalam observasi lapang.

\section{REFERENSI}

[1] Denny and T. Kalima, "Keanekaragaman Tumbuhan Obat pada Hutan Rawa Gambut Punggualas, Taman Nasional Sebangau, Kalimantan Tengah (The diversity of Medicinal Plant of Punggualas Peat Swamp Forest, Sebangau National Park, Central Kalimantan)," Bul. Plasma Nutfah, vol. 22, no. 2, pp. 137-148, 2016.

[2] G. Wicaksono, Serangga Terbang Punggualas Taman Nasional Sebangau: Panduan Visual dan Identifikasi Lapangan Capung dan Кири-Кири. Kalimantan Tengah: WWF-Indonesia, 2015.

[3] G. Wicaksono, K. P. Makur, and A. Baihaqi, Herpetofauna Punggualas Taman Nasional Sebangau: Panduan Visual Dan Identifikasi Lapangan Amfibi dan Reptil. Kalimantan Tengah: WWF-Indonesia, 2015.

[4] D. T. Iskandar and W. R. Erdelen, "Conservation of Amphibians and Reptiles in Indonesia: Issues and
Problems," Amphib. Reptil. Conserv., vol. 4, no. 1, pp. 60-87, 2006.

[5] W. Heyer, M. Donnelly, R. McDiarmid, L. Hayek, and M. Foster, Measuring and Monitoring Biological Diversity: Standard Methods for Amphibians. Washington: Smithsonian Books, 1994.

[6] T. M. Doan, "Which Methods Are Most Effective for Surveying Rain Forest Herpetofauna?," J. Herpetol., vol. 37, no. 1, pp. 72-81, 2003.

[7] M. Kusrini, Metode Survei dan Penelitian Herpetofauna. Bogor: IPB Press, 2019.

[8] J. Malkmus, R., Manthey, U., Vogel, G., Hoffmann, P. \& Kosuch, Amphibians \& Reptiles of Mount KInabalu (North Borneo). Germany, 2002.

[9] R. Inger, R. Stuebing, T. Grafe, and J. Dehling, A Field Guide to the Frogs of Borneo. 3rd ed. Kinabalu: Natural History Publication (Borneo), 2017.

[10] R. Stuebing, R. Inger, and B. Lardner, A Field Guide To The Snakes of Borneo. 2nd ed. Kinabalu: Natural History Publication (Borneo), 2014.

[11] I. Das, A Field Guide to The Reptiles of South-East Asia. London: Bloomsbury Publishing Plc, 2010.

[12] IUCN, "The IUCN Red List of Threatened Species," $2020 . \quad$ [Online]. Available: https://www.iucnredlist.org/. [Accessed: 20-Feb-2020].

[13] S. J. Husson et al., "Biodiversity of The Sebangau Tropical Peat Swamp Forest, Indonesian Borneo," Mires Peat, vol. 22, no. November, 2018.

[14] E. Purwaningsih and Mumpuni, "Parasitic Nematodes From Turtles: New Apecies And New Record From Indonesia," J. Coast. Life Med., vol. 3, no. 8, pp. 607$611,2015$. 